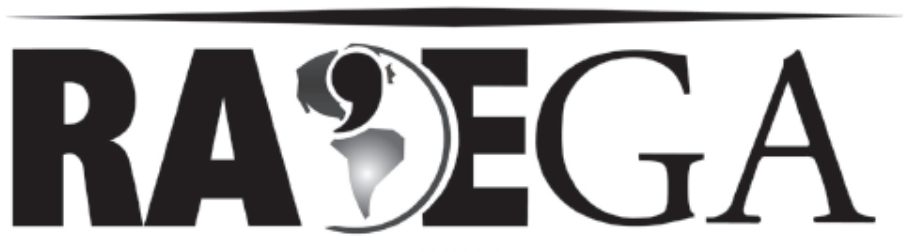

O ESPAÇO GEOGRÁFICO EM ANÁLISE

\title{
A CONTRIBUIÇÃO DA PERCEPÇÃO AMBIENTAL NOS ESTUDOS DAS ÁREAS VERDES
}

\section{THE CONTRIBUTION OF ENVIRONMENTAL PERCEPTION ON STUDIES OF GREEN AREAS}

\author{
Renata Geniany Silva Costa ${ }^{1}$ \\ Marlene Muno Colesanti ${ }^{2}$
}

\section{RESUMO}

Os problemas ambientais enfrentados hoje são fudamentalmente problemas humanos. Neste sentido, entendendo as áreas verdes como elemento essencial na melhoria do ambiente urbano e da saúde da população, procurouse apresentar a percepção ambiental como um caminho a ser trilhado nos estudos acerca das áreas verdes públicas, como praças, parques e jardins. Donde a finalidade é conhecer os sentimentos que influenciam na formação de juízos de valor e orientam atitudes e ações sobre estes espaços.

Palavras-chave: Áreas Verdes, Percepção, Atitude ambiental.

\section{ABSTRACT}

The environmental problems faced today are essentialy human problems. In this sense, understanding the green areas as an essential element to improve the urban environment and population's health, is looked forward to show the environmental perception as a way to go on studies of the public green areas, such as plazas, parks and gardens. Hence the purpose is to know the feelings that influence the formation of value judgments and guide attitudes and actions about these spaces.

Keywords: Green Areas, Perception, Environment attitude.

\footnotetext{
${ }^{1}$ Licenciada em geografia pela Universidade Federal de Juiz de Fora e Mestranda em Geografia pela Universidade Federal de Uberlândia renatageniany@yahoo.com.br

${ }^{2}$ Geógrafa, Professora Doutora do Instituto de Geografia (IG) da Universidade Federal de Uberlândia MG mmuno@ufu.br
} 


\section{INTRODUÇÃO}

As áreas verdes vêm ganhando importância como um dos elementos fundamentais que contribuem na melhoria da qualidade do ambiente e de vida da população urbana. Apesar da dificuldade na definição dos conceitos de qualidade ambiental e de qualidade de vida, Oliveira (1983 apud Mazzeto (2000) destaca que a qualidade do meio ambiente está intimamente ligada à qualidade de vida, sendo que vida e meio ambiente são inseparáveis e esta interação deve estar sempre em equilíbrio.

Visto que, o comportamento humano tem grande influência para manter a qualidade ambiental (SEWEL, 1978 apud MAZZETO, 2000), entende-se que, compreender a percepção torna-se um fator imprescindível para se conhecer os juízos de valor e atitudes que orientaram ações sobre o ambiente.

Os problemas urbanos enfrentados hoje, tais como poluição do ar e da água, enchentes, barulho em excesso, entre outros, causam sérios prejuízos à saúde física e mental da população. Com vias de minimizar estes problemas, as áreas verdes, em especial as públicas, vem sendo tema discutido na comunidade acadêmica por diferentes trabalhos (NUCCI, 1996; HENKEOLIVEIRA, 1996; MAZZEI et al, 2007). Nestes estudos, a ênfase está na investigação dos benefícios trazidos pelas áreas verdes para a saúde e bemestar da população citadina, partindo-se da premissa de que as áreas verdes contribuem de maneira eminente para uma melhoria da qualidade ambiental e de vida da população ao desenvolver funções ecológicas, sociais e de lazer. Funções estas, essenciais para proporcionar o bem-estar da população em seu relacionamento com o ambiente.

Entretanto, apesar do crescente interesse pela compreensão dos aspectos mais distintamente humanos, influenciado pelo movimento romantico, a partir da década de 1950 na geografia, ainda são poucos os estudos que ultrapassam a visão positivista dos estudos científicos tradicionais para explorar a natureza das experiências humanas a partir da busca pela compreensão dos sentimentos que a população tem em relação ao ambiente, neste caso, as áreas verdes como parques, praças e jardins. 
Entende-se que os estudos de percepção constituem uma visão impar, uma vez que, a investigação e compreensão dos sentimentos e valores têm um papel importante para formação de juízos de valor e atitudes que orientam ações sobre estes espaços.

Logo, procurou-se no presente trabalho apresentar a percepção ambiental como um possível caminho a ser trilhado nos estudos acerca das áreas verdes públicas como praças, parques e jardins, que buscam contribuir com informações importantes para a manutenção e multiplicação destes espaços no meio urbano.

Para atingir este objetivo, procurou-se primeiramente apresentar o que se entende no presente trabalho por áreas verdes, visto a necessidade de esclarecimento derivada da natureza dos estudos que abarcam este conceito. Posteriormente, procurou-se apresentar o estudo da percepção e suas principais características como um meio de estudo das áreas verdes. E, ao fim, foi apresentada a mudança de atitude em relação à natureza instaurada entre os séculos XV e XVIII, que forneceram o legado ideológico da atualidade.

\section{AS ÁREAS VERDES URBANAS}

Diferentes conceitos são empregados para classificar a vegetação presente nas cidades. Cobertura vegetal, áreas verdes, espaços livres, arborização urbana, muitas vezes, aparecem em muitos trabalhos como sinônimos, mesmo representando conceitos diferentes (LIMA, et al. 1994).

A falta de consenso entre estes conceitos pode estar atrelada ao fato de a vegetação ser tratada sob difentes olhares, seja entre as ciências como Geografia, Agronomia, Arquitetura, Engenharia Florestal, entre outras, seja no âmbito dos órgãos públicos responsáveis pela vegetação nas cidades.

Mesmo sendo muito ricas as contribuições dos estudos realizados atualmente, essa falta de consenso acaba gerando conflito na hora de avaliar a vegetação presente nas cidades e prejudica a comparação entre os estudos realizados. 
Muitas são as definições empregadas para se referir as áreas verdes urbanas. Contudo, para este trabalho o termo área verde é entendido segundo Cavalheiro, et al. (1999), como um tipo especial de espaço livre onde o elemento fundamental de composição é a vegetação, que devem satisfazer três objetivos principais: ecológico-ambiental, estético e de lazer e devem servir a população, proporcionando uso e condições para recreação. Assim, áreas como parques urbanos, jardins e praças, que satisfazem os requisitos descritos, podem ser consideradas áreas verdes.

Enquanto espaço recreacional, estas áreas devem proporcionar recreação física e psicológica ao ser humano, contato com a natureza, interação social, e relaxamento devido à vida estressante da sociedade moderna, ou seja, devem proporcionar ainda, condições para atividades que ambientes interiores não podem oferecer devido às suas limitações (COLESANTI, 1994).

As diferentes funções (ecológica, social e de lazer, por exemplo) desenvolvidas pelas áreas verdes podem contribuir para a melhoria da saúde da população e do ambiente físico. A função ecológica, que influência diretamente na ambiência urbana, está intimamente ligada às atividades fisiológicas desempenhadas pela planta durante toda a sua vida.

A vegetação pode contribuir para melhorar a ambiência urbana sob diferentes aspectos, dos quais podemos citar, o controle micro-climático, a minimização da poluição e do barulho, atuando como barreira acústica, modificando a velocidade e direção dos ventos.

Pode também contribuir para o bem-estar psicológico dos indivíduos, a saúde física e mental da população. A vegetação auxilia num relativo isolamento dos usuários no interior de espaços como praças, parques e jardins (MASCARÓ, 2005), possibilitando o descanso e um "passar o tempo" fora caos urbano.

Assim, a vegetação quando planejada pode promover diferentes benefícios ao meio ambiente e à população urbana, o que lhe fornece grande status e valor. Este valor é tanto econômico, entendido enquanto valoração 
dos espaços urbanos; alvo da especulação imobiliária, quanto subjetivo, ligado ao prazer, à beleza e a sensação de tranqüilidade.

Os estudos das áreas verdes são frequentemente associados à questão ambiental no que se refere à qualidade de vida nos centros urbanos. Essa relação é derivada da crescente preocupação com degradação do ambiente urbano intrínseco ao processo de urbanização.

Todavia, apesar do aumento do conhecimento a respeito da relevância das áreas verdes, ainda é observado uma negligência na manutenção e multiplicação destas areas, constatadas em estudos que procuram avaliar a sua presença/ausência através de índices e mapeamentos (HENKE-OLIVEIRA, 1996; COSTA \& FERREIRA, 2007a, 2007b).

Em algumas cidades, devido à dinâmica de urbanização, áreas destinadas às praças ou jardins acabam dando lugar a novas construções. Quando não, muitos parques e praças têm seus espaços destinados para fins diferentes do qual foram criados, que seria o de proporcionar condições de lazer e recreação.

Tal contradição mostra que os estudos acerca das áreas verdes precisam seguir por caminhos alternativos, que tenham como objetivo complementar os estudos existentes, buscando uma maneira de compreender como a vegetação vem ganhando ênfase e acaba, muitas vezes, sendo negligenciada no ambiente urbano.

Ora, áreas verdes públicas como praças, parques urbanos e jardins devem atender ás necessidades e anseios da população, para serem desejados e mantidos pela população. Logo, uma alternativa está nos estudos de percepção ambiental e na busca por compreender como a população enxerga estes espaços, o quê ela anseia, e, quê relação estabelece com estes espaços.

\section{CONTRIBUIÇÃO DA PERCEPÇÃO AMBIENTAL}

A percepção da população sobre as áreas verdes como um elemento indispensável para a melhoria da qualidade do ambiente urbano depende de 
diferentes fatores, dos quais podemos citar o valor atribuído a estes lugares, a população em questão e como essa população percebe as condições ambientais e de vida no momento histórico vivenciado.

De acordo com Tuan (1980), os estudos sobre o ambiente deveriam se preocupar com a formação de atitudes e valores. Afinal, para que possam ser delimitadas soluções duradouras para minimizar os problemas ambientais, é preciso, antes de tudo, conhecer a nós mesmos. Pois, para o geógrafo Tuan (1980) problemas ambientais são fundamentalmente problemas humanos.

Os estudos a partir da abordagem perceptiva buscam conhecer a maneira pela qual os seres humanos respondem ao seu ambiente físico, ou seja, a percepção que dele têm e o valor que nele depositam.

A principal direferença entre o processo mental humano e animal é que o homem tem uma capacidade altamente desenvolvida para o comportamento simbólico. "Um símbolo é um repositório de significados. Os significados emergem das experiências mais profundas que se acumulam através do tempo" (TUAN, 1980, p.166).

Estas experiências acumuladas são formadas por uma longa sucessão de percepções que dão origem às atitudes que orientam ações para com o meio ambiente circundante. Logo, a relação para com o meio ambiente tem influência direta dos sentimentos e valores que são depositados nestes.

Dessa forma a percepção constitui numa importante análise em trabalhos que se ocupam dos estudos que tratam das áreas verdes, proporcionando uma melhor compreensão das relações que os seres humanos mantêm com estes espaços.

A percepção segundo Tuan, é tanto a resposta dos sentidos aos estímulos externos, como a
atividade proposital, na qual certos fenômenos são claramente
registrados, enquanto outros retrocedem para a sombra ou são
bloqueados. Muito do que percebemos tem valor para nós,
para a sobrevivência biológica, e para propiciar algumas
satisfações que estão enraizadas na cultura (TUAN,1980,
p.05).

Da realidade percebida à ação, a percepção sofre várias influências, como se passasse por diferentes filtros. Estes filtros são fisiológicos, sensoriais 
e culturais (OKAMOTO, 2002). Segundo Okamoto (op.cit. p.58) "Todas as pessoas enxergam e reconhecem tão somente coisas de seus interesses, conforme o universo de seus pensamentos. A realidade é restrita a esse enfoque, e a nossa mente é seletiva."

Todo fluxo de informações que chegam ao individuo é filtrado respeitando os elementos valorizados pelo indivíduo. E com o tempo, essas informações começam a ser, cada vez mais, dirigidas por valores culturais.

A partir desses "filtros", configura-se um mundo singular organizado pelo indivíduo, ou seja, toda percepção do mundo envolve a utilização de categorias mentais com as quais os seres humanos classificam e ordenam a massa de fenômenos ao seu redor. E, de acordo com Thomas (1996), uma vez apreendidas estas categorias, passa a ser difícil ver o mundo de outra maneira. O sistema dominante de classificação toma posse, moldando a percepção e o comportamento.

Ao tentar compreender como é organizado o mundo para o indivíduo Tuan (1980) escreve sobre o que ele mesmo chamou de "estruturas e respostas psicológicas comuns".

Para compreender estas respostas psicológicas comuns, torna-se necessário, entender, antes de qualquer coisa, que aquele geógrafo apresenta a percepção enquanto uma atividade que sofre influências derivadas tanto dos aspectos do indivíduo, da cultura, quanto do meio ambiente em que está inserido.

Assim, Tuan (1980) escreve que a percepção varia segundo os sentidos, o grupo e o indivíduo. Os sentidos são a visão, tato, audição e olfato, as quais Tuan (op.cit.) se refere como "traços comuns em percepção", ou seja, estes seriam os filtros sensoriais comuns a todas as pessoas. O grupo para este autor está ligado aos traços orientados pela cultura. E o indivíduo, representado pela singularidade da percepção de cada pessoa, ou seja, ainda que a percepção seja orientada por regras universais delimitadas pela cultura, ela também é idiossincrática, ligada a fisiologia humana e a diversidade de temperamento, como talento, atitudes, idade e gênero. 
Os apectos ligados aos sentidos, ao grupo e ao indivíduo e o meio ambiente interagem mutuamente gerando a percepção que o indivíduo tem do seu meio ambiente.

O meio ambiente físico, portanto, também exerce grande influência na percepção, atitude e visão de mundo. O ambiente interfere na interpretação dos indícios visuais, até a estruturação de mundo pela atividade mental do indivíduo, tendo como base as características do seu habitat.

Não podemos, também, conceber a percepção ambiental disvinculada da idéia de cultura. A cultura é o contexto de todos os acontecimentos, é algo dentro do qual os processos podem ser descritos de forma inteligível, "o homem é um animal amarrado a teias de significados que ele mesmo teceu" (GEERTZ 1989, p. 15). Assim, a cultura seria essas teias e sua análise.

Os conceitos de "cultura" e "meio ambiente" se superpõe da mesma forma que "homem" e "natureza" (TUAN, 1980). Conhecer a história cultural e a experiência de um grupo em seu ambiente físico fornece perspectivas complementares sobre a percepção e formação de atitude ambiental.

Dentre as características comuns ao grupo na percepção ou "respostas psicológicas comuns", uma merece maior atenção e diz respeito às "oposições binárias" (Tuan, 1980). Esta característica apresenta que a mente humana tende a selecionar pares entre segmentos percebidos no continuum da natureza (os fenômenos) e atribuir significados opostos (antíteses) a cada par. Estas antinomias bipolares são derivadas da experiência humana, como vida e morte, macho e fêmea, por exemplo. Embora, as duas partes sejam vistas como complementares, elas são desiguais. E representa uma característica importante na compreensão da valorização das áreas verdes.

Essa resposta psicológica comum às pessoas pode ser responsável pelos dilemas humanos enfrentados na atualidade, como a dualidade Cidade e Campo (Thomas, 1988). Entretanto, a antítese da cidade que melhor se encaixaria neste dilema seria o selvagem; ao campo. Visto que, a nostalgia em relação ao campo está na recuperação dos valores ambientais ligados à idéia do selvagem, perdidos no urbano. 
Neste sentido, é possível afirmar que é na negação do urbano que surge a valorização da natureza intocada. É nesta oposição que se fundamenta o resgate de atividades ligadas a natureza, onde a proximidade com os elementos da natureza, com animais selvagens e com a vegetação de maneira geral, torna-se objeto de anseio da população.

Os valores ambientais requerem sua antítese para definí-lo (TUAN, 1980). Sendo assim, valores como saúde, liberdade, alegria e tranquilidade, são sentimentos pela natureza encorajados pelas pressões da vida urbana. $O$ campo e a natureza, portanto, são encarados como um ideal de um modo diferente de vida, na medida em são uma reação à cidade.

Logo, saber como os indivíduos percebem o ambiente em que estão inseridos, suas fontes de satisfação e insatisfação é de fundamental importância para que se possa compreender melhor suas expectativas, julgamentos e condutas (FAGGIONATO, 2007). O estudo da percepção pode ser direcionado ao estudo das áreas verdes visando, assim, compreender os valores atribuídos a estas áreas pela população.

Existem diferentes trabalhos, dentre os quais se pode citar os de Bley (1995) e Colesanti \& Marques (1999), que vêm estudando os espaços frequentados como avenidas, praças, parques associados á percepção ambiental.

Não obstante, é preciso compreender que o modo de experienciar a natureza dentro do ambiente urbano de hoje, constitui-se fruto de uma mudança cultural que inaugurou a modernidade e, encontra-se na base de nossa experiência civilizatória.

\section{MUDANÇAS NA ATITUDE AMBIENTAL: ÁRVORES, PARQUES E JARDINS}

Nem sempre, na história da humanidade, a natureza foi percebida como algo contemplativo, belo, agradável. A forma de tratar a natureza transformada e integrada a malha urbana de hoje, reflete a visão de mundo (GEERTZ, 1989) de uma população construída através dos tempos.

O filósofo Keith Thomas, em seu livro "O Homem e Mundo Natural", publicado em 1933, faz uma análise do modo de pensar das pessoas na 
Inglaterra nos trezentos anos que inauguram a modenidade. Com o foco no modo que a população tratava os animais e as plantas, Thomas mostra como se passou da violência sobre o mundo natural à contemplação da natureza.

Muito deste momento histórico construiu o modo de pensar herdado por nós. Afinal, no Brasil, devido ao processo de colonização, muito do que se conhece do passado está mergulhado na cultura e intimamente ligado à história da Europa.

Thomas (1996) mostra que pensar que o homem dava maior valor à natureza antes da industrialização é um erro. Ao contrário, foi a redução das matas em benefício de pastos e lavoura, em resposta às forças do mercado, que instaurou a nostalgia pelas árvores na cidade.

As florestas, até o século XVIII eram consideradas "selvagens" (de silva, selva), sinônimo de rusticidade e perigo. Segundo Thomas (1996), um dicionário poético do século XVII, sugeria como epítetos apropriados a uma floresta, "terrível", "sombria", "selvagem", "deserta", "agreste", "melancólica", "desabitada" e "assoada por feras". A mata, portanto, era o lar das feras, dos animais e não do homem culto e civilizado.

Desde os tempos mesolíticos, o progresso humano dependeu de arrancar e destruir árvores. O processo de destruição da mata simbolizava o triunfo da civilização. As matas que não eram cultivadas eram vistas, como um obstáculo ao progresso e a vida culta (THOMAS, 1996).

Segundo Thomas (1996) os primeiros parques urbanos tiveram origem na Ingleterra, no século XVIII e objetivavam oferecer um ambiente favorável para os animais de caça. A prática de caçar fornecia as florestas um valor recreativo, ainda que fosse privilégio apenas dos senhores de classe. Tais parques constituíram importante símbolo de posição social.

Ainda que sob argumentos utilitários, houve no final do século XVIII uma tendência a tratar bem as árvores e plantas que culminou numa contemplação do verde. Sob o entendimento de natureza, os parques, jardins e árvores estavam ligados a idéia de beleza, dignidade, prazer, estética, abrigo, nobreza, "lugar perfeito", "cenário-modelo" (THOMAS, 1996). 
Junto aos pressupostos utilitários do uso e lucro da madeira, a constituição do cenário urbano a partir da deterioração do ambiente e da saúde da população, provocou movimentos de modificação da ordem urbana estabelecida.

De inicio, a questão sanitária foi foco de ações sob o discurso médico, que forneceu elementos ideológicos que justificaram intervenções e reorganizações urbanas na época. Assim, os modelos ideais de cidade, foram construídos sob a utopia de uma cidade higiênica (física e moral), salubre, bela, hamônica, equlibrada, racional, eficiente, arborizada, ordenada, planejada, funcional, etc (COSTA, 2002). Esse modelo dominou as idéias de préurbanistas e urbanistas progressitas dos séculos XIX e XX, e deram origem a diferentes propostas de cidades utópicas, tal como a idéia de cidades jardins.

As cidades jardins segundo Tuan (1980) foi uma cidade projetada por Ebenezer Howard em 1919, como um ideal derivado da idéia da vida no campo. "A ênfase no aspecto "jardim" se traduziu na excessiva plantação de árvores." (TUAN, 1980, p.281). Entretanto, segundo Thomas (1996), a idéia de cidade jardim já havia sido formulada por John Evelyn em 1661.

Entre os séculos XVII e XVIII predominavam, assim, uma teoria higienista (COSTA, 2002) e uma estética (THOMAS, 1996), que tinham em comum a ênfase na importância das árvores como parte essencial do cenário arquitetônico urbano.

Esse pensamento foi formulado em função da "decadência urbana e pelo anseio por uma vida sadia." (TUAN, 1980, p.282), sob a idéia de que a natureza poderia exercer uma influência benéfica sobre a saúde e a moral das pessoas.

Essa nova forma de "olhar" a natureza, a partir da experiência urbana marcada pela degradação ambiental, impulsionou segundo Carvalho (2008) o surgimento de um sentimento estético e moral de valorização da natureza selvagem e não transformada pelos humanos, afirmada na nostalgia da natureza intocada.

Contudo, a natureza que viria a ocupar o meio urbano, é uma natureza "intermediária" entre as atinomias "cidade" (principal expressão da ação 
antrópica) e "selvagem" (sob a idéia de "ausência" da interferência antrópica, próximo da vida tal como nos foi dada).

Tão logo, surgiria uma razão mais duradoura que a simples idéia de conservação das árvores ligada à crença de que as matas acrescentariam beleza e dignidade à paisagem. O prazer oferecido pela presença das árvores, cada vez mais ornamentais, e a presença da água, oferecia satisfação estética, produzidos pelos reconhecidos jardins paisagísticos do século XVIII. As árvores, então, se tornaram objetos de reconhecido prazer e valor estético.

As árvores haviam deixado de ser um símbolo da barbárie ou mera mercadoria, para se tornar parte indispensável do cenário de vida da classe superior (THOMAS, 1996).

Se neste período, é bem verdade que esse sentimento pode ser considerado uma sensibilidade burguesa (CARVALHO, 2008), hoje, no entando, esse ideário prodomina no discursso de toda sociedade, atingindo diferentes classes sociais.

Essa mudança cultural de valores e padrões de comportamento para com a natureza forneceu o legado ideológico da contemporaneidade, visto que os problemas urbanos, mesmo que em níveis diferenciados dos que se apresentaram na cidade industrial do século XVIII, ainda fazem parte do cotidiano das cidades.

\section{CONSIDERAÇÕES FINAIS}

A principal contribuição do estudo de percepção aplicado as áreas verdes está em conhecer o mundo de aspirações e anseios daqueles que são os principais usuários desses espaços no meio urbano. O ambiente ideal de um planejador, nem sempre coincide com o ambiente ideal das pessoas que vão usufruir mais diretamente desses espaços como os parques, praças e jardins.

O estudo da percepção permite mostrar que o campo da mente humana apresenta uma variedade de interpretações do ambiente a nossa volta. É 
possível observar que pessoas vivendo na mesma cidade, no mesmo bairro, mesmo assim percebem mundos diferentes.

As visões de mundo são influenciadas por uma rede de sentimentos, objetos e referenciais que, são tanto pessoais, como derivados do grupo que a pessoa faz parte, que precisam ser conhecidos pelos profissionais e planejadores desses espaços, visto que essa rede é responsável pela formação de atitudes e valores que se refletem no espaço.

Como foi apresentado, é preciso considerar, que a atitude em relação à natureza pode mudar com o tempo. Cada ambiente é enxergado através de valores ao qual o indivíduo está adaptado no momento histórico vivênciado. Pode-se observar que nem sempre as árvores, matas e parques foram símbolo de lazer e descanso. Esta mesma vegetação que é valorizada hoje, já foi outrora símbolo de rusticidade e barbárie.

Ainda que diferentes estudos apontem para as áreas verdes como elementos importantes para a melhoria da qualidade ambiental e de vida, contraditóriamente, ainda é possível observar muitos desses espaços relegados ao segundo plano. Assim, o desafio dos profissionais ligados ao planejamento de áreas verdes, comprometidos com a qualidade ambiental e com a satisfação da população, é exatamente tentar compreender e reconhecer os valores que são depositados nestas áreas e, considerar como estes valores subjetivos da experiência humana podem ser aplicados no planejamento e manejo de áreas verdes, como parques urbanos, praças e jardins na cidade.

\section{REFERÊNCIAS}

BLEY, L. Os Estudos de Percepção em Geografia na UFPR. In: BLEY, L. (Org.) Percepção em Geografia. Curitiba: UFPR, 1995. Caderno 2. p.2-8.

CARVALHO, Isabel, C. M. Educação Ambiental: a formação do sujeito ecológico. São Paulo: Cortez, 2008.

CAVALHEIRO, F.; NUCCI, J.C.; GUZZO, P.; ROCHA, Y.T. Proposição de Terminologia para o Verde Urbano. Boletim Informativo da Sociedade Brasileira de Arborização Urbana. SBAU: AnoVII, no3 - jul/ago/set de 1999. Rio de Janeiro, RJ, 1999. 
COLESANTI, M. T. M. Por uma Educação Ambiental: o Parque do Sabiá, em Uberlândia, MG. (tese de doutoramento). Rio Claro, SP: Unesp, 1994.

COLESANTI, M. T. M.; MARQUES, D. V. Uma Proposta de educação ambiental para o Bosque John Kennedy - Araguari. In: XI SEMANA DE GEOGRAFIA, 1999, Uberlândia: EDUFU, 1999. v.1. p.58-58.

COSTA, Maria, C. L. A cidade e o pensamento médico: uma leitura do espaço urbano. Mercator - Rev. De Geografia da UFC. 1(2):61 - 69, 2002.

COSTA, R. G. S.; FERREIRA, C. C. M. Estudo biogeográfico das áreas verdes e da arborização ligada ao sistema viário na região central da cidade de Juiz de Fora, MG. Revista Sociedade \& Natureza, Uberlândia - MG. 8 (22):143-156, 2007 a.

Avaliação do Índice de Áreas Verdes (IAV) em 26 Regiões Urbanas na Região Central da cidade de Juiz de Fora, Minas Gerais. In: XII SIMPÓSIO DE GEOGRAFIA FÍSICA APLICADA, 2007. Natal, RN: CCHLA, 2007b. p. 1-19.

FAGGIONATO, S. Percepção Ambiental. Disponível em $<$ http://educar.sc.usp.br/biologia/textos/m_a_txt4.html> Acesso em 23 de fev. 2007.

GEERTZ, C. A interpretação das culturas. Rio de Janeiro: Guanabara, 1989.

HENKE - OLIVEIRA, C. Planejamento ambiental na Cidade de São Carlos (SP) com ênfase nas áreas públicas e áreas verdes: diagnósticos e propostas. 1996. Dissertação (Mestrado). São Carlos, SP, UFSCar, 1996.

LIMA, A. M. L. P.; CAVALHEIRO, F.; NUCCI, J.C.; SOUZA, M.A.B.; FIALHO, N.; DEL PICCHIA, P.C.D. Problemas de Utilização na Conceituação de termos como Espaços Livres, Áreas Verdes e Correlatos. In: II CONGRESSO BRASILEIRO SOBRE ARBORIZAÇÃO URBANA, 1994. São Luis, MA: Sociedade Brasileira de Arborização Urbana, 1994. p. 539-553.

MASCARÓ, L; MASCARÓ J. Vegetação Urbana. Porto Alegre: Editora +4, 2ºed, 2005.

MAZETTO, F. A. P. Qualidade de Vida, Qualidade ambiental e meio Ambiente Urbano: Breve Comparação de Conceitos. Revista Sociedade \& Natureza, Uberlândia - MG. 12 (24): 21-31, 2000.

MAZZEI, K; COLESANTI, M. T. M.; SANTOS, D. G. Áreas Verdes Urbanas, Espaços Livres para o Lazer. Revista Sociedade e Natureza, Uberlândia - MG. 19 (1): 33-43, 2007.

$\mathrm{NUCCl}$, João Carlos. Qualidade Ambiental e Adensamento: um estudo de planejamento da paisagem do distrito de Santa Cecília (MSP). 1996. Tese (Doutorado). São Paulo-SP. USP, 1996.

OKAMOTO, J. Percepção ambiental e comportamento: visão holística da percepção ambiental na arquitetura e na comunicação. São Paulo: Mackenzie, 2002.

THOMAS, K. O homem e o mundo natural: mudanças de atitudes em relação às plantas e aos animais (1500-1800). São Paulo: Cia das Letras, 1996.

TUAN, Y. F. Topofilia: um estudo da percepção, atitudes e valores do meio ambiente. São Paulo: DIFEL. 1980. 